\title{
CALCULATION OF THE VEHICLES STRESS-DEFORMED STATE WHILE TRANSPORTING THE LIQUID CARGO
}

Oleksii Grevtsev $^{1}$, Ninel Selivanova ${ }^{1}$, Pavlo Popovych ${ }^{2}$, Liubomyr Poberezhny ${ }^{3, *}$, Oksana Shevchuk ${ }^{2}$, Igor Murovanyi ${ }^{4}$, Andrii Hrytsanchuk ${ }^{3}$, Liubov Poberezhna ${ }^{3}$, Vasyl Zapukhliak ${ }^{3}$,Galyna Hrytsuliak ${ }^{4}$

${ }^{1}$ National Transport University, Kyiv, Ukraine

${ }^{2}$ West Ukrainian National University, Ternopil, Ukraine

${ }^{3}$ Ivano-Frankivsk National Technical University of Oil and Gas, Ivano-Frankivsk, Ukraine

${ }^{4}$ Lutsk National Technical University, Lutsk, Ukraine

*E-mail of corresponding author: lubomyrpoberezhny@gmail.com

\section{Resume}

To calculate the stress-deformed state of road-tanker metal structures during the liquid cargo transportation, the solution for bending axially and symmetrically loaded circular plates is proposed, which is based on the theory of elasticity approach. Dependencies for calculating stresses and displacements under arbitrary load law and support type are substantiated. Deformation of the support under the action of axisymmetric loading leads to appearance of a temperature field.

\section{Article info}

Received 31 January 2020

Accepted 14 July 2020

Online 19 November 2020

\section{Keywords:}

trailers,

metal structures of vehicles,

liquid cargoes,

axisymmetric problem,

thermodynamically reverse process,

bend of a circular plate

ISSN 1335-4205 (print version)

ISSN 2585-7878 (online version)

\section{Introduction and literature review}

According to analysis of operation conditions of vehicles for transporting the liquid cargoes, the dynamic loads and influence of external environment, in particular temperature and precipitation, are the main factors that cause destruction of assembly units (load-bearing systems and tanks of vehicles), their parts (supports of tanks, etc.), as well as connections [1-7]. This fact contributes to formation of wet films on surfaces of vehicles, with regard to condition of surfaces: coating, roughness, hardness etc. The constant impact of combinations of these factors causes damage with subsequent destruction, the most characteristic of which are [8-17]: fatigue damage, atmospheric corrosion, corrosion-mechanical wear, corrosion fatigue, corrosion cracking, fretting - corrosion. The study of the vehicles' condition after 1-3 years of operation makes it possible to conclude: more than $70-80 \%$ of constituent units and machine parts are subjected to corrosion in one way or another, [1-17]. Therefore, the corrosion damage and fatigue fracture are objective and logical results of influence of the environment, dynamic loads and thermodynamically unstable metal materials of the vehicles' parts. The fatigue damage to metal structures, as well as the corrosive one, causes vehicle failure and weight loss, intensifies joint wear, changes in the surface roughness of parts, reduces fatigue strength, causing various cracks and metal breaks. As a result, the reliability, efficiency and resource of the machines and their components are reduced; the cost of repair and the elimination of the consequences of failures increase. The service life of parts often reduces in practice up to 50\% due to fatigue fractures. According to analysis of fractures of parts, knots and details of thin sheet steel, the inner surfaces of containers for toxic chemicals are destroyed most quickly [9-17]. Therefore, during the operation of vehicles, especially when transporting the liquid cargo, the random complex combinations of different power factors affects the tank and elements of the bearing systems. This fact is stipulated by the random nature of the sources of disturbances (transport modes, inequalities of the road, geometry, etc.).

Based on the research results of metal structures of tanks (including their supports) for transporting the liquid cargoes, the following tasks can be solved:

- $\quad$ estimation of the stress strain state of metal structures (in particular tanks and their supports during the transportation of the liquid cargoes) in order to identify and improve the maximum loaded elements to reduce the metal structure; 
- distribution of stresses in the maximum loaded cross sections of elements to predict the reliability of vehicles.

Deformation of the solid elastic medium is not always purely a mechanical phenomenon. Nearly every deformation is accompanied by thermal effects and therefore an attempt to describe the behavior of the environment, ignoring the thermo-mechanical interaction within the environment, is not always feasible. Temperature change in the body can occur as a result of a deformation process, as well as for extraneous reasons. External load (surface, volume) causes the body deformation and at the same time causes the change of the temperature field in it. The change in temperature is $\theta=\mathrm{T}-\mathrm{t}_{0}$, where $\mathrm{T}$ is the absolute temperature points of the body, $\mathrm{t}_{0}$ is the temperature of the unstressed body. Therefore, during the deformation the temperature changes of the points of the body and can lead to the absorption or release of heat by elastic uninsulated body and its interaction with the environment. The deformation process is very slow, i.e., it is thermodynamically reversible. The temperature change $\theta$ is very small and does not cause changes in existing physical and mechanical characteristics of the material body. Its accounting allows to accurately solve the equation of elasticity for bending of round plates under the action of forces normally applied according to arbitrary loading law with any type of section, which previously was impossible to do.

\section{Methodology}

The exact solution of equations of the theory of elasticity in the closed form for round plates with axisymmetric loading is possible only taking into account the temperature change, which appears at deformation from action of normally added forces. The magnitude of the temperature change is very small $(\approx 2 \div 3 \mathrm{~K})$, but its consideration makes it possible to accurately solve the problem of the theory of elasticity for bodies of rotation with axisymmetric deformation without any simplified hypotheses, except for the general linear theory of elasticity. There is no need to use different approximate numerical methods of solution, such as FEM.

Therefore, in order to solve these problems with maximum accuracy, it is advisable to apply the provisions of the theory of elasticity, which will provide adequate simulation of stresses and displacements under arbitrary loads and types of supports.

The exact solution of elasticity problem is known [18] to be available only for the case of a solid round plate loaded with a uniformly distributed pressure of constant intensity. Thus, the form of loading is assumed arbitrary, as well as the type of plate resistance.

Differential equilibrium equations in a cylindrical coordinate system are deduced [18]

$$
\begin{aligned}
& \Delta u_{1}-\frac{u_{1}}{r^{2}}+\frac{e, 1}{1-2 v}-2 \frac{(1+v)}{(1-2 v)} \alpha \theta,_{1}=0 ; \\
& \Delta u_{3}-\frac{u_{1}}{r^{2}}+\frac{e, 3}{1-2 v}-2 \frac{(1+v)}{(1-2 v)} \alpha \theta,_{3}=0 ; \\
& \sigma_{11,1}+\sigma_{13,1}+\frac{\sigma_{11}-\sigma_{22}}{r}=0 ; \\
& \sigma_{13,1}+\sigma_{33,3}+\frac{1}{r} \sigma_{13}=0 .
\end{aligned}
$$

In Equations (1) and (2), the index after the comma denotes the partial derivative with respect to the corresponding coordinate: $r$ or $z ; u_{1}$ and $u_{3}$ are components of radial and axial movements, respectively; $\Delta u$ - Laplace operator for movements $u_{i}(i=1,3) ; \sigma_{11}, \sigma_{12}, \sigma_{13}$ respectively, the components of radial, circumferential, axial and tangential stresses; $\sigma_{33}$ is explained in Equation (6).

The Hooke's law [19] determines the stress components

$$
\begin{aligned}
\sigma_{i j} & =2 G\left(e_{i j}+\frac{v}{1-2 v} e \delta_{i j}-\frac{1+v}{1-v} \alpha \theta \delta_{i j}\right) \\
i, j & =1,2,3
\end{aligned}
$$

based on the well-known dependencies between deformations and movements:

$e_{11}=u_{1,1} ; e_{22}=\frac{1}{r} u_{1} ; e_{33}=u_{3,1} ; 2 e_{13}=u_{1,3}+u_{3,1}$,

where $\delta_{i j}$-Kronecker delta symbol; $\alpha$ and $v$-respectively, coefficients of linear thermal expansion and Poisson's ratio; $e=e_{11}+e_{22}+e_{33}$ - volumetric expansion; $G=\frac{E}{2(1+v)}$ - shear module; $E$ - modulus of elasticity.

To solve the system of equilibrium Equations (1), the equation of thermal conductivity should be considered [19]:

$\Delta \theta+\frac{1}{\lambda} W=0$,

where $W$ - amount of heat that is released or absorbed per unit of the body volume during the deformation; $\lambda$ thermal conductivity; $\Delta \theta=\theta,,_{11}+\frac{1}{r} \theta,{ }_{11}+\theta,{ }_{33}$.

To solve the problem of bending the round plates under the action of an arbitrary axisymmetric intensity load $P(r)$, the normal axial stress $\sigma_{33}$ should be determined. Therefore, the method based on translational approximations should be applied. Thus, after the transformations, we obtain:

$\sigma_{33}=-P(r) \frac{12}{h^{3}}\left(\frac{z^{3}}{6}-\frac{z h^{2}}{8}-\frac{h^{3}}{24}\right)$.

Equation (6) meet conditions:

$\sigma_{33}=-P(r)$, if $z=-\frac{h}{2}$ and $\sigma_{33}=0$,

where $z=-\frac{h^{2}}{2}$,

where $h$ - the thickness of the round plate. 


\section{Results and discussion}

Based on Equation (6), the problem of bending the plate is further solved applying the function $\phi_{(r, z)}$. To solve this problem accurately, a polytrophic thermodynamic process (neither isothermal nor adiabatic) is studied. The function $\psi_{(r, z)}$ is related to the thermoelastic movement potential by the formula [19]:

$\phi_{(r, z)}=\frac{1+v}{1-x} \psi(r, z)$.

For this case, the movement is defined:

$$
\begin{aligned}
& u_{1}(r, z)=\frac{1+v}{1-v} \psi, \\
& u_{3}(r, z)=\frac{1+v}{1-v} \psi,
\end{aligned}
$$

The volumetric expansion $e$ is derived from Equation (4), with taking into account Equation (9):

$$
\begin{aligned}
& e=e_{11}+e_{22}+e_{33}= \\
& =\frac{1+v}{1-v}\left[\psi, 11+\frac{1}{r} \psi_{, 1}+\psi_{, 33}\right]= \\
& =\frac{1+v}{1-v} \Delta \psi
\end{aligned}
$$

Substituting Equations (9) and (10) into the system of Equations (1), one obtains:

$$
\begin{aligned}
& \frac{2(1+v)}{1-v}(\Delta \psi)_{, 1}-\frac{2(1+v)}{1-v} 2 \theta_{, 1}=0 \\
& \frac{2(1+v)}{1-v}(\Delta \psi)_{, 3}-\frac{2(1+v)}{1-v} 2 \theta_{, 3}=0 .
\end{aligned}
$$

Integrating Equation (11) the first equation with respect to $r$ and the second equation with respect to $z$, the formula for definition of a temperature variable is deduced:

$$
2 \theta=\Delta \psi
$$

Based on the Hooke's law [20], the elasticity is found. The temperature change $\theta$ is derived from Equation (12).

Then:

$$
\begin{aligned}
\sigma_{13} & =\frac{E}{1-v} \psi{ }_{, 13} ; \sigma_{33}=-\frac{E}{1-v} \frac{1}{r}\left(r \psi_{, 1}\right)_{, 1} ; \\
\sigma_{11} & =-\frac{E}{1-v}\left(\frac{1}{r} \psi_{, 1}+\psi_{, 3}\right) ; \\
\sigma_{11} & =-\frac{E}{1-v}\left(\psi_{, 11}+\psi_{, 3} 3\right) .
\end{aligned}
$$

To solve the elasticity theory equations, the movement function $\psi(r, z)$ should be chosen in such a way as to satisfy the boundary conditions for a specific problem.

Thus, the curvature of the round plates in the exact formulation of the problem from the standpoint of the theory of elasticity is considered below. The given plates are loaded symmetrically with respect to the axis of rotation $z$ by forces $P(r)$ applied perpendicular; forms of loading and types of supports are arbitrary.
The stress $\sigma_{33}$ in Equation (6), which satisfies Equation (7), is compared to stress $\sigma_{33}$ in Equation (13). After transformations, the differential equation for determining the function $\psi(r, z)$ is developed:

$$
(r \psi, 1)_{, 1}=\frac{1-v}{E} \frac{12}{h^{3}}\left(\frac{z^{3}}{6}-\frac{z h^{2}}{8}+\frac{h^{3}}{24}\right) r P(r) .
$$

Integrating Equation (14) with respect to $r$ in the range from $a_{1}$ to $r$, the formula is deduced:

$$
\begin{aligned}
& \psi_{, 1}=\frac{1-v}{E} \frac{12}{h^{3}}\left(\frac{z^{3}}{6}-\frac{z h^{2}}{8}+\frac{h^{3}}{24}\right) \frac{1}{r} . \\
& \int_{a_{1}}^{r} r P(r) d r+\frac{1}{r} f_{1}(z),
\end{aligned}
$$

where $f_{1}(z)$ - arbitrary integration function; $a_{1}$ - radius of the central hole of the plate.

For the case, if there is no hole in the metal plate under study $\left(a_{1}=0\right)$, then, $f_{1}(z)$ is equal to zero for finite movements $u(r)$. Therefore, Equation (15) is integrated with respect to $r$ in the range from $a_{1}$ to $r$, resulting in:

$$
\begin{aligned}
& \psi(r, z)=\frac{1-v}{E} \frac{12}{h^{3}}\left(\frac{z^{3}}{6}-\frac{z h^{2}}{8}+\frac{h^{3}}{24}\right) \times \\
& \times \int_{a 1}^{r} \frac{1}{r} \int_{a 1}^{r} r P(r) d r d r+f_{1}(z) \ln \frac{r}{a}+f_{2}(z),
\end{aligned}
$$

where $f_{2}(z)$ - arbitrary integration function.

To rationally simplify calculations, a solid plate $\left[a_{1}=0 ; f_{1}(z)=0\right]$ should be considered. Then:

$$
\begin{aligned}
& \psi(r, z)=\frac{1-v}{E} \frac{12}{h^{3}}\left(\frac{z^{3}}{6}-\frac{z h^{2}}{8}+\frac{h^{3}}{24}\right) \times \\
& \times \int_{0}^{r} \frac{1}{r} \int_{0}^{r} r P(r) d r d r+f_{2}(z) .
\end{aligned}
$$

Differentiating Equation (17) with respect to $r$ and $z$ :

$\psi_{(r, z)}=\frac{1-v}{E} \frac{12}{h^{3}}\left(\frac{z^{3}}{6}-\frac{h^{2}}{8}\right) \frac{1}{r} \int_{0}^{r} r P(r) d r$

and substituting $\psi_{, 13}$ into Equation (13), one obtains:

$\sigma_{13}=\frac{6}{h^{3}}\left(z^{2}-\frac{h^{2}}{4}\right) \frac{1}{r} \int_{0}^{r} r P(r) d r$.

The boundary conditions for Equation (19) are satisfied integrally at the edge of the round plate. Therefore, to meet the boundary conditions providing, $r=a$, the stress $\sigma_{13}$ at the edge of the plate should be reduced to the support reaction: 

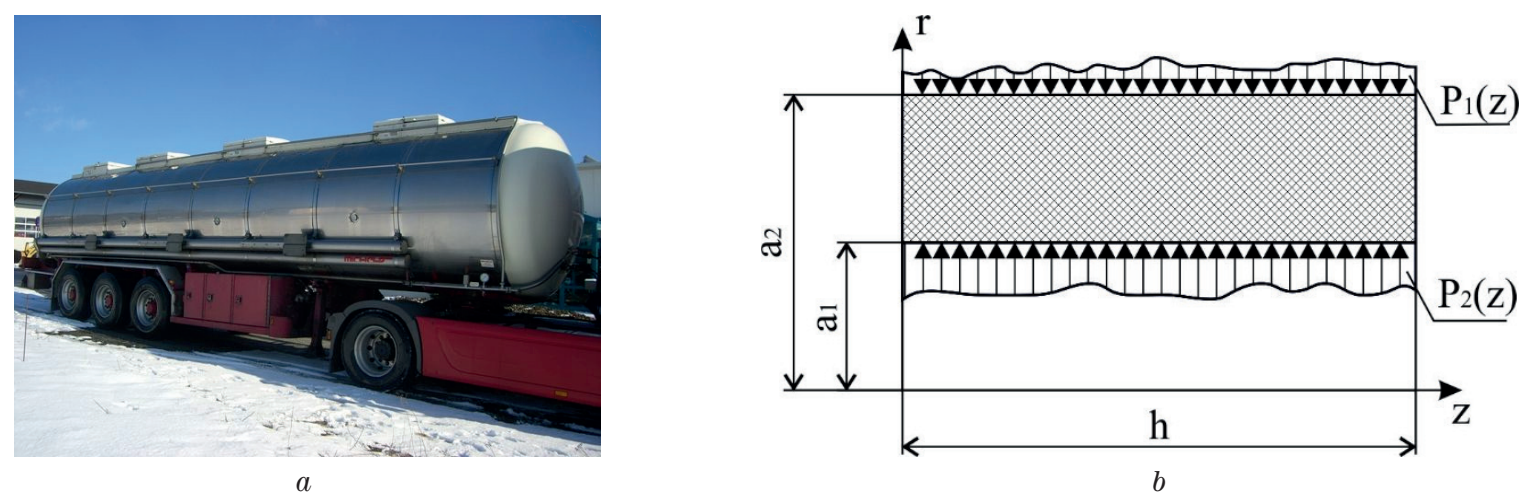

Figure 1 a-tank of a vehicle for transporting the liquid cargoes; $b$-schematization of the tank element, solid round plate with an arbitrary type of support, loaded $P(r)_{x}$

$A=\left[\int_{-\frac{h}{2}}^{\frac{h}{2}} \sigma_{13} d z\right]_{r=a}=-\frac{1}{a} \int_{0}^{r} r P(r) d r$

Thus, the stresses in Equation (19) satisfy the boundary conditions on the planes $z= \pm \frac{h}{2}$ integrally at the edge of the surface.

Substituting Equation (17) into Equation (13) for the normal radial stress $\sigma_{11}$ and deriving the function $f_{2}(z)$ from the boundary conditions $\sigma_{11}=0$, providing $r=a$, one obtains:

$\sigma_{11}=\frac{12}{h^{3}} \times$

$\times\left\{\begin{array}{l}\left(\frac{z^{3}}{6}-\frac{z h^{2}}{8}+\frac{h^{3}}{24}\right) \times \\ \times\left[\frac{1}{r^{2}} \int_{0}^{r} r P(r) d r-\frac{1}{a^{2}} \int_{0}^{a} r P(r) d r\right]+ \\ +Z\left[\int_{0}^{r} \frac{1}{r} \int_{0}^{r} r P(r) d r d r-\int_{0}^{a} \frac{1}{r} \int_{0}^{a} r P(r) d r d r\right]\end{array}\right\}$.

For the stress $\sigma_{22}$ in Equations (13):

$$
\begin{aligned}
& \sigma_{22}=-\frac{12}{h^{3}} \times \\
& \times\left\{\begin{array}{l}
\left(\frac{z^{3}}{6}-\frac{z h^{2}}{8}+\frac{h^{3}}{24}\right) \times \\
\times\left[P(r)-\left(\frac{1}{r^{2}} \int_{0}^{r} r P(r) d r-\frac{1}{a^{2}} \int_{0}^{a} r P(r) d r\right)\right]+ \\
+z\left[\int_{0}^{r} \frac{1}{r} \int_{0}^{r} r P(r) d r d r-\int_{0}^{a} \frac{1}{r} \int_{0}^{a} r P(r) d r d r\right]
\end{array}\right\} .
\end{aligned}
$$

Theobtainedstressessatisfy theequilibriumEquation(2) and the boundary conditions: $\sigma_{33}=-P(r)$ if $z=-\frac{h}{2}$; $\sigma_{33}=0$ where $z=\frac{h}{2} ; \sigma_{13}=0$ where $z= \pm \frac{h}{2}$; and integrally on the edge of the plate: $\sigma_{11}=0$ where $r=a$.

The plate support conditions make it possible to determine the exact values of movements by Equation (8) using Equation (17).

Movements $u_{1}$ and $u_{2}$ :

$$
\begin{aligned}
& u_{1}(r, z)=\frac{1+V}{1-V}\left[\psi \psi_{, 1}+\frac{1}{r}\left(A_{5} z-A_{3}\right)\right]+ \\
& +r\left(A_{4} z+A_{6} \frac{1}{2}\right) \\
& u_{1}(r, z)=\frac{1+V}{1-V}\left[\psi_{, 3}+A_{5} \ln r\right]- \\
& -A_{4}\left(\frac{V}{1-V} z^{2}+\frac{r^{2}}{2}\right)-\frac{V}{1-V} z A_{6}+A_{7} .
\end{aligned}
$$

where $A_{i}$ - arbitrary integration constants.

Based on Equation (23), the formula is developed:

$$
\begin{aligned}
& \sigma_{13}=\frac{E}{1-V} \psi_{, 13} ; \sigma_{33}=-\frac{E}{1-V} \frac{1}{r}\left(r \psi_{, 1}\right)_{, 1} \\
& \sigma_{11}=\frac{E}{1-V}\left[\begin{array}{l}
-\frac{1}{r} \psi_{, 1}-\psi_{, 33}-\frac{1}{r^{2}} \times \\
\times\left(A_{5} z-A_{3}\right)+A_{4} z+A_{6} \frac{1}{2}
\end{array}\right] \\
& \sigma_{22}=\frac{E}{1-V}\left[\begin{array}{l}
\psi, 11-\psi, 33 \\
\times\left(A_{5} z-A_{3}\right)+A_{4} z+A_{6} \frac{1}{2}
\end{array}\right] .
\end{aligned}
$$

Equations (23) and (24) are exact solutions of equilibrium Equations (1) and (2); after substitution, Equations (1) and (2) are transformed into identities. The function $\psi(r, z)$ must satisfy Equation (12). Based on this equation, the temperature variable $\theta(r, z)$, occurred due to the action of external loads, could be determined, as well as the dependence $\psi(r, z)$ on the boundary conditions.

To illustrate the elastic and thermodynamic reflexivity of the above-considered problems of the theory of elasticity for axisymmetric deformation of plates, the solution should be simplified by assuming that $P(r)=P_{0}=$ const (see Figure 1).

Then, for the movement in Equation (17) one gets:

$$
\begin{aligned}
& \psi(r, z)=\frac{1-V}{E} \frac{12}{h^{3}} P_{0}\left(\frac{z^{3}}{6}-\frac{z h^{2}}{8}+\frac{h^{3}}{24}\right) \times \\
& \times \frac{r^{2}}{4}+f_{2}(z),
\end{aligned}
$$

while for stresses in Equation (19) is obtained:

$$
\sigma_{13}=\frac{3}{h^{3}} P_{0}\left(z^{3}-\frac{h^{2}}{4}\right) r
$$


The magnitude of the support reaction at the edge of the plate:

$$
A=-\frac{a}{2} P_{0} .
$$

Radial stresses in Equation (21) and circular stresses in Equation (22) coincide:

$\sigma_{11}=\sigma_{22}=\frac{3 z}{h^{3}} P_{0}\left(a^{2}-r^{2}\right)$.

For the function $f_{2}(z)$ one obtains:

$$
\begin{aligned}
& f_{2}(z)=\frac{1-V}{E} \frac{6}{h^{3}} P_{0}\left(\frac{z^{5}}{120}-\frac{z^{3} h^{2}}{48}+\frac{z^{3} a}{12}\right)+ \\
& +C_{1} C_{1} z+C_{2}
\end{aligned}
$$

where $C_{1}$ and $C_{2}$ - arbitrary integration constants.

Based on Equation (9), the displacements are found:

$$
\begin{aligned}
& u_{1}(r, z)=\frac{1+V}{1-V} \psi_{, 1}=\frac{1+V}{E} \frac{12}{h^{3}} P_{0} \times \\
& \times\left(\frac{z^{3}}{6}-\frac{z^{8} h^{2}}{8}+\frac{h^{3}}{24}\right) \frac{r}{2} u_{3}(r, z)=\frac{1+V}{1-V} \psi_{, 3}= \\
& =\frac{1+V}{E} \frac{3}{2 h^{3}} P_{0} \times \\
& \times\left[r^{2}\left(z^{2}-\frac{h^{2}}{4}\right)-\left(\frac{z^{3}}{6}-\frac{h^{2} z^{2}}{4}+\frac{z h^{3}}{6}+z^{2} a^{2}\right)\right]+ \\
& +\frac{1+V}{1-V} C_{1} .
\end{aligned}
$$

The radial movement in Equation (30) affects the resistance of the plate in such a way that it allows the movement of the plate in the direction of the vertical axis (Figure 1).

The normal movement in Equation (31) allows fixing the points of the plate edges in different ways to prevent their vertical displacement.

As an example, the hinge fixing of the plate contour points, in the middle plane, could be considered, $u_{3}=0$; $r=a ; z=0$. Satisfying these boundary conditions for movement in Equation (30) and an arbitrary integration constant $C_{1}$, the formula is deduced:

$$
\frac{1+V}{1-V} C_{1}=\frac{1+V}{E} \frac{3}{2 h^{3}} P_{0} \frac{a^{2} h^{2}}{4} .
$$

After substitution Equation (31) into Equation (30), one obtains:

$$
\begin{aligned}
& u_{3}(r, z)=\frac{1+V}{E} \frac{3}{2 h^{3}} P_{0} \times \\
& \times\left[\begin{array}{l}
r^{2}\left(z^{2}-\frac{h^{2}}{4}\right)+\frac{a^{2} h^{2}}{4}- \\
-\left(\frac{z^{3}}{6}-\frac{h^{2} z^{2}}{4}+\frac{z h^{3}}{6}+z^{2} a^{2}\right)
\end{array}\right] .
\end{aligned}
$$

The stresses corresponding to movements in Equations (28) and (32) are developed:

$$
\begin{aligned}
& \sigma_{33}=-\frac{6}{h^{3}} P_{0}\left(\frac{z^{3}}{3}-\frac{h^{2} z}{4}+\frac{h^{3}}{12}\right) ; \\
& \sigma_{13}=\frac{3}{h^{3}} P_{0}\left(z^{2}-\frac{h^{2}}{4}\right) r ; \\
& \sigma_{11}=\sigma_{22}=\frac{3}{h^{3}} P_{0}\left(a^{2}-r^{2}\right) z .
\end{aligned}
$$

Based on Equations (25) and (29), follows:

$$
\begin{aligned}
& \psi(r, z)=\frac{1-V}{E} \frac{6}{h^{3}} P_{0} \times \\
& \times\left[\begin{array}{l}
\left(\frac{z^{3}}{6}-\frac{z h^{2}}{8}+\frac{h^{3}}{24}\right) \frac{r^{2}}{4}- \\
-\left(\frac{z^{5}}{120}-\frac{z^{3} h^{2}}{48}+\frac{z^{2} h^{3}}{48}+\frac{a^{2} z^{2}}{12}\right)+\frac{a^{2} z^{2}}{16} z
\end{array}\right]+ \\
& +C_{2} .
\end{aligned}
$$

where $C_{2}$ - arbitrary integration constant.

The temperature variable $\theta(r, z)$ occurred due to the action of external loads $P_{0}$ in the plate under study is developed

$\alpha \theta=\Delta \psi_{, 11}+\frac{1}{r} \psi_{, 1}+\psi_{, 33}$.

Substituting Equation (34) into Equation (35), one obtains:

$\theta(r, z)=\frac{(1-V)}{E \alpha} \frac{6}{h^{3}} P_{0} \times$
$\times\left[\frac{z^{3}}{6}-\frac{z h^{2}}{8}+\frac{h^{3}}{24}-\left(a^{2}-r^{2}\right) \frac{z}{2}\right]$.

External surface and volume loads cause the body deformation and the occurrence of temperature changes in it [20]. Temperature change is $\theta=T-T_{0}$, where $T$ - the absolute temperature of the body point; $T_{0}$ - the temperature of the unstressed body when $t=0$.

Therefore, during the deformation, temperature of an arbitrary point of the body changes. As a result, an elastic uninsulated body absorbs or releases heat during its interaction with the environment [21]. This temperature change of the bent round plate is determined by the dependence in Equation (36).

Providing that the load $P_{0}=0$ is reset, voltage in Equation (33) and temperature change in Equation (36) disappear. Then, the plate acquires the initial unstressed and undeformed state. The deformation process is very slow, i.e. it is thermodynamically reversible [22].

The deformation of the plate and the temperature change in it under external load are under study. Substituting $z=-\frac{h}{2}$ into Equation (32), the dependence describing the compression ratio of the upper layers of the plate in the given direction is developed:

$u_{3}\left(r_{1}-\frac{h}{2}\right)=\frac{1+V}{E} \frac{3 h}{64} P_{0}>0$. 
For the case of a lower surface of the plate where $z=+\frac{h}{2}$ :

$u_{3}\left(r_{1} \frac{h}{2}\right)=-\frac{1+V}{E} \frac{3 h}{64} P_{0}<0$.

Resulting in a stretching area.

Based on Equation (32), for the compressed section of the plate, the temperature change is deduced as:

$$
\begin{aligned}
& \theta\left(r_{1}-\frac{h}{2}\right)=\frac{1-V}{E \alpha} \frac{3}{h^{2}} P_{0}\left(\frac{h^{2}}{3}+a^{2}-r^{2}\right) \geq 0, \text { or } \\
& T\left(r_{1}-\frac{h}{2}\right)=T_{0}+\frac{1-V}{E \alpha} \frac{3}{h^{2}} P_{0}\left(\frac{h^{2}}{3}+a^{2}-r^{2}\right) \times \\
& \times(r \leq a),
\end{aligned}
$$

while for the stretched, area due to the bending, it is:

$$
\begin{aligned}
& \theta\left(r_{1} \frac{h}{2}\right)=-\frac{1-V}{E \alpha} \frac{3}{h^{2}} P_{0}\left(a^{2}-r^{2}\right) \leq 0, \text { or } \\
& T\left(r_{1} \frac{h}{2}\right)=T_{0}-\frac{1-V}{E \alpha} \frac{3}{h^{2}} P_{0}\left(a^{2}-r^{2}\right)(r \leq a) .
\end{aligned}
$$

Therefore, the temperature of the compressed area will be slightly higher than the temperature of the stretched area. In other words, the compressed zone releases heat $\left(T>T_{0}\right)$ and the stretched zone absorbs it $\left(T<T_{0}\right)$, i.e. there is a heat exchange of the plate with the external environment. K. Zener [23] developed a similar theory; it was experimentally confirmed for a thin plate with bending deformations.

Substituting the temperature variable in Equation (36), which appears when the round plate is bent under the action of a uniformly distributed load of constant intensity, into Equation (5), the power of the heat flow in the sections of the plate is found.

$$
W=-\lambda \Delta \theta=-\lambda \frac{(1-V)}{E \alpha} \frac{18 z}{h^{3}} P_{0} .
$$

For the case of a compressed section of the plate, where $z=-\frac{h}{2}$.
The heat released:

$$
W=\lambda \frac{(1-V)}{E \alpha} \frac{9}{h^{2}} P_{0}>0 .
$$

For the stretched area due to the bending $z=\frac{h}{2}$. The heat absorbed:

$$
W=-\lambda \frac{(1-V)}{E \alpha} \frac{9}{h^{2}} P_{0}<0 .
$$

As a result, due to the thermal conductivity, a heat flow occurs, due to bending, from the compressed to the stretched area.

\section{Conclusion}

In the analytical calculations of the stress strain state of metal structures of vehicles for the transportation of the bulk cargo, the theory of elasticity approach should be applied. The problem solution for the case of bending of the axisymmetrically loaded round plates is presented. Analytical dependences for calculation of stresses and movements in metal plates at arbitrary forms of loading and types of supports are substantiated. The obtained solutions prove that the action of external forces leads to the temperature change and heat flow occurrence due to the deformation of the bent tank metal structure.

Deformation and change in the temperature fields in the plate due to the external axisymmetric loading were considered first. The results indicate that the temperature of the compressed zone of the bent plate will be slightly above the temperature of the stretched zone, that is, the compressed area generates heat $\left(\mathrm{T}>\mathrm{t}_{0}\right)$, while the stretched area absorbs it $\left(\mathrm{T}<\mathrm{t}_{0}\right)$ and there is the heat exchange with the external environment.

\section{References}

[1] GAYDAR, S. M. Protection of agricultural machinery from corrosion and wear using nanotechnology. Dissertations for Doctor of technical sciences. Moscow, 2011.

[2] POPOVYCH, P., SHEVCHUK, O., DZYURA, V., POBEREZHNA, L., DOZORSKYY, V., HRYTSANCHUK, A. Assessment of the influence of corrosive aggressive cargo transportation on vehicle reliability. International Journal of Engineering Research in Africa [online]. 2018, 38, p. 17-25. ISSN 1663-3571, eISSN 1663-4144. Available from: https://doi.org/10.4028/ www.scientific.net/JERA.38.17

[3] POPOVYCH, P. V., LYASHUK, O. L., SHEVCHUK, O. S., TSON, O. P., POBEREZHNA, L. Y., BORTNYK, I. M. Influence of organic operation environment on corrosion properties of metal structure materials of vehicles. INMATEH Agricultural Engineering [online]. 2017, 52(2), p. 113-118. ISSN 2068-4215, eISSN 2068-2239. Available from: https://inmateh.eu/ volumes/old-volume/volume-52-no-2-2017/article/influence-of-organic-operation-environment-on-corrosion-propertiesof-metal-structure-materials-of-vehicles.

[4] POPOVYCH, P. V., LYASHUK, O. L., MUROVANYI, I. S., DZYURA V. O., SHEVCHUK O. S., MYNDYUK, V. D. The service life evaluation of fertilizer spreaders undercarriages. INMATEH Agricultural Engineering [online]. 2016, 50(3), p. 39 -46. ISSN 2068-4215, eISSN 2068-2239. Available from: https://inmateh.eu/volumes/old-volume/volume-50-no-3-2016/ article/the-service-life-evaluation-of-fertilizer-spreaders-undercarriages 
[5] LYTVynenKO, I. V., MARUSChAK, P. O., LUPENKO, S. A., POPOVYCH, P. V. Modeling of the ordered surface topography of statically deformed aluminum alloy. Materials Science [online]. 2016, 52, p. 113-122. ISSN 1068-820X, eISSN 1573-885X. Available from: https://doi.org/10.1007/s11003-016-9933-1

[6] POPOVICH, P. V., BARNA, R. A. Influence of operating media on the fatigue fracture of steels for elements of agricultural machines. Materials Science [online]. 2014, 50(3), p. 377-380. ISSN 1068-820X, eISSN 1573-885X. Available from: https://doi.org/10.1007/s11003-014-9729-0

[7] MARUSCHAK, P., PANIN, S., DANYLIUK, I., POBEREZHNYI, L., PYRIG, T., BISHCHAK, R., VLASOV, I. Structural and mechanical defects of materials of offshore and onshore main gas pipelines after long-term operation. Open Engineering [online]. 2015, 5(1), p. 365-372. eISSN 2391-5439. Available from: https://doi.org/10.1515/eng-2015-0045

[8] POBEREZHNYI, L. Y., MARUSHCHAK, P. O., SOROCHAK, A. P., DRAGANOVSKA, D., HRYTSANCHUK, A. V., MISHCHUK, B. V. Corrosive and mechanical degradation of pipelines in acid soils. Strength of Materials [online]. 2017, 49(4), p. 539-549. ISSN 0039-2316, eISSN 1573-9325. Available from: https://doi.org/10.1007/s11223-017-9897-x

[9] MARUSCHAK, P., POBEREZNY, L., PRENTKOVSKIS, O., BISHCHAK, R., SOROCHAK, A., BARAN, D. Physical and mechanical aspects of corrosion damage of distribution gas pipelines after long-term operation. Journal of Failure Analysis and Prevention [online]. 2018, 18(3), p. 562-567. ISSN 1547-7029. Available from: https://doi.org/10.1007/ S11668-018-0439-Z

[10] SHCHURIN, K. V. Prediction and increase of fatigue life of bearing systems of agricultural tractor machinery. Dissertations for Doctor of technical sciences. Orenburg: OPI. 1994.

[11] POBEREZHNY, L., MARUSCHAK, P., HRYTSANCHUK, A., POBEREZHNA, L., PRENTKOVSKIS, O, STANETSKY, A. Impact of gas hydrates and long-term operation on fatigue characteristics of pipeline steels. Procedia Engineering [online]. 2017, 187, p. 356-362. ISSN 1877-7058. Available from: https://doi.org/10.1016/J.Proeng.2017.04.386

[12] HEVKO, B. M., POPOVICH, P. V., DIACHUN, A. Y., LYASHUK, O. L., LIUBACHIVSKYI, R. O. The Study of bulk material kinematics in a screw conveyor-mixer. In: International Symposium of ISB-INMA TEH. Agricultural and Mechanical Engineering: proceedings. 2015.

[13] YAVORSKYI, A. V., KARPASH, M. O., ZHOVTUliA, L. Y., POBEREZHNY, L. Y., MARUSCHAK, P. O., PRENTKOVSKIS, O. Risk management of a safe operation of engineering structures in the oil and gas sector. In: 20th International Scientific Conference Transport Means: proceedings. 2016. p. 370-373.

[14] PATIL, M. R. B., KULKARNI, V. V. (2018). Finite element analysis of support designs for road tankers. International Research Journal of Engineering and Technology. 2018, 5(2), p. 836-843. ISSN 2395-0056, eISSN 2395-0072.

[15] ROMERO, J. A., OTREMBA, F., LOZANO-GUZMAN, A. A. Simulation of liquid-cargo-vehicle interaction under lateral and longitudinal accelerations. In: 9th International Conference on Computational Methods: Proceedings. 2018. p. 6-10.

[16] HAN, M., DAI, J., WANG, C. M., ANG, K. K. Hydrodynamic analysis of partially filled liquid tanks subject to 3d vehicular manoeuvring. Shock and Vibration [online]. 2019, 6943879. ISSN 1070-9622, eISSN 1875-9203. Available from: https:// doi.org/10.1155/2019/6943879

[17] POPOVYCH, P. V., MAHLATYUK, L. ., KUPOVYCH, R. B. Influence of organic fertilizers on the corrosionelectrochemical characteristics of low-carbon steels. Materials Science [online]. 2014, 50(2), p. 284-289. ISSN 1068-820X, eISSN 1573-885X. Available from: https://doi.org/10.1007/s11003-014-9719-2

[18] NOVOZHILOV, V. V. Foundations of the nonlinear theory of elasticity. Courier Corporation, 1999. ISBN 0-486-40684-9.

[19] SEDOV, L. I. Mechanics of continuous media. 4. ed. World Scientific, 1997. ISBN 978-9971-5-0728-2.

[20] LANDAU, L. D., LIVSHYTS, Y. M. Theory of elasticity. 7. ed. Nauka, 1987. ISBN 978-0750626330.

[21] PARKUS, H. Thermoelasticity. Springer Science \& Business Media, 2012. ISBN 978-3-7091-8447-9.

[22] TIMOSHENKO, S. P., GOODIER, J. N. Theory of elasticity. 3. ed. New York: Mcgraw Hill, 1970. ISBN 9780070647206.

[23] FENG, J. Machines, energy, entropy (in Russian). Moscow: Mir, 1986. ISBN 978-0966081381. 